\title{
Efeito de duas intensidades de colheita de madeira na estrutura de uma floresta natural na região de Paragominas, Pará
}

\author{
Luciana Maria de Barros FRANCEZ1, João Olegário Pereira de CARVALHO², Fernando Cristóvam da Silva \\ JARDIM $^{3}$, Beatriz QUANZ ${ }^{4}$, Klewton Adriano Oliveira PINHEIRO5
}

\begin{abstract}
RESUMO
Foram estudadas as mudanças na estrutura de 108 ha de uma floresta primária submetida a duas intensidades de colheita de madeira, na Fazenda Rio Capim, pertencente à Cikel Brasil Verde Madeiras Ltda., no município de Paragominas, Pará. Os dados foram coletados, em dois períodos (2003, antes da exploração, e 2004, após a exploração) em 36 parcelas permanentes quadradas de 0,25 ha, estabelecidas aleatoriamente na área, sendo $12 \mathrm{em}$ floresta não-explorada: Testemunha - $\mathrm{T}_{0} ; 12 \mathrm{em}$ floresta explorada com colheita apenas do fuste comercial das árvores: Tratamento - $\mathrm{T}_{1}$; e $12 \mathrm{em}$ floresta explorada com colheita do fuste e dos resíduos lenhosos: Tratamento - $T_{2}$. Em 2003 foram registrados 4469 indivíduos com DAP $\geq 10 \mathrm{~cm}$, nas 36 parcelas amostradas (9ha). Sete meses após a exploração (2004), foram observados na área 4531 indivíduos com DAP $\geq 10 \mathrm{~cm}$, sendo 4330 vivos. Lecythis idatimon, Poecilanthe effusa, Rinorea flavescens, Eschweilera grandiflora, Eschweilera pedicellata, Inga sp., Protium spp., Vouacapoua americana, Guatteria poeppigiana e Eschweilera coriacea foram as dez espécies mais importantes, tanto antes como após a exploraçáo. A estrutura da floresta, tanto no $\mathrm{T}_{1}$ como no $\mathrm{T}_{2}$, sofreu alteraçóes significantes devido à exploração a que foi submetida. Entretanto, não foram verificadas diferenças significativas entre os três tratamentos, sugerindo que com a intensidade de exploração aplicada, mais a retirada adicional dos resíduos, a floresta manteve as características semelhantes à floresta original, apesar do menor estoque de árvores adultas de espécies comerciais. Recomendam-se estudos sobre a regeneração natural $(\mathrm{DAP} \leq 10 \mathrm{~cm})$, silvicultura pós-colheita e crescimento da floresta.
\end{abstract}

PALAVRAS-CHAVE: Estrutura horizontal, exploração de impacto reduzido, parcelas permanentes, Amazônia.

\section{Effect of two harvest intensities on the structure of a natural forest in Paragominas, Pará}

\begin{abstract}
Changes in the forest structure were analyzed considering two harvest intensities in 108ha of primary forest in the Rio Capim Forest Management Unit, belonging to Cikel Brasil Verde Madeiras Ltda., in the municipality of Paragominas, Pará. Data were collected in 2003 (before harvesting) and 2004 (after harvesting) in 36 0.25ha permanent sample plots, randomly distributed in the area (12 in unlogged forest, 12 in logged forest and 12 in logged forest plus extraction of coarse woody debris). Before logging (2003), 4469 trees with $\mathrm{DBH} \geq 10 \mathrm{~cm}$ were recorded in the 36 plots (9ha sample). Seven months after logging (2004), the number of trees increased to 4531 but only 4330 were found alive. Lecythis idatimon, Poecilanthe effusa, Rinorea flavescens, Eschweilera grandiflora, Eschweilera pedicellata, Inga sp., Protium spp., Vouacapoua americana, Guatteria poeppigiana and Eschweilera coriacea were the ten most important species both before and after logging. Forest structure, in the two harvest intensities, had significant changes due to the logging. But there were no significant changes between the two logged areas, suggesting that the extraction of the coarse woody debris after logging did not cause significant damage to the remaining forest. Forest structure changed slightly after logging but these changes were not significant among the three communities. Despite the reduction in adult tree stock of commercial species due to logging and coarse woody debris extraction, the stand kept characteristics similar to the original forest. Studies on natural regeneration $(\mathrm{DBH} \leq 10 \mathrm{~cm})$, pos-harvesting silviculture and growth of the forest are recommended.
\end{abstract}

KEYWORDS: Forest structure, reduced impact logging, permanent sample plot, Amazon.

\footnotetext{
1 Secretaria de Estado de Meio Ambiente - SEMA/PA. E-mail: lucianafrancez@yahoo.com.br

2 Empresa Brasileira de Pesquisa Agropecuária Amazônia Oriental. E-mail: olegario.carvalho@gmail.com

${ }^{3}$ Universidade Federal Rural da Amazônia. E-mail: fernando.jardim@ufra.edu.br

${ }^{4}$ Secretaria de Estado de Meio Ambiente - SEMA/PA. E-mail: quanzster@gmail.com

${ }^{5}$ Escola Agrotécnica Federal de Castanhal -EAFC/PA. E-mail: klewton.pinheiro@gmail.com
} 


\section{INTRODUÇÃO}

Os recursos madeireiros e não-madeireiros da floresta amazônica estáo sendo explorados de forma irracional, uma vez que há a predominância da colheita de madeira sem planejamento, caracterizada pela máxima retirada de madeira por unidade de área, das espécies de valor comercial, promovendo danos severos à floresta remanescente (Pinto et al., 2002). O impacto da exploraçâo desordenada, na regiấo, é significativo.

Os danos causados às árvores, à regeneração natural e ao solo, decorrentes da exploração madeireira em uma determinada área, devem ser avaliados criteriosamente, pois têm influência direta no correto manejo da floresta. Além disso, deve-se buscar informaçốes básicas relacionadas à autoecologia das espécies envolvidas (Martins et al., 2003).

É necessário que o plano de manejo possa prever a intensidade com que os danos causados pela exploraçáo irão ocorrer na estrutura da floresta, garantindo assim sua sustentabilidade (Pinto et al., 2002). Tal plano deve conter as técnicas e os métodos de corte, de extração e de transporte mais adequados, no sentido de causar o mínimo possível de impacto à estrutura da floresta.

$\mathrm{Na}$ aplicação de qualquer sistema de manejo, em regime de rendimento sustentado em florestas tropicais da Amazônia, é imperativo que se analise a estrutura da floresta, do ponto de vista qualitativo e quantitativo, permitindo a intervenção no povoamento numa intensidade que não provoque alterações severas, permitindo que a floresta atinja seu máximo potencial produtivo (Jardim e Hosokawa, 1986/1987).

Este estudo teve como objetivo avaliar o impacto da exploração florestal na estrutura de uma floresta de terra firme na regiāo de Paragominas, PA, submetida a duas intensidades de colheita de madeira, com a finalidade de gerar informaçôes básicas em ecologia e silvicultura de florestas naturais, para aprimorar o sistema de manejo florestal, que utiliza técnicas de exploração de impacto reduzido.

\section{MATERIAL E MÉTODOS}

A área de estudo está localizada na Fazenda Rio Capim, pertencente a Cikel Brasil Verde Madeiras Ltda., no município de Paragominas. O município está localizado no nordeste Paraense, mesorregiāo Sudeste Paraense e microrregião de Paragominas, entre as coordenadas de $2^{\circ} 25^{\prime}$ e $4^{\circ} 09^{\prime} \mathrm{S}$ e $46^{\circ} 25^{\prime}$ e $48^{\circ} 54^{\prime} \mathrm{W} \mathrm{Gr}$, tendo sua sede localizada no entroncamento do Km 0 da PA 256 com o Km 15 da PA 125 às margens da rodovia BR - 010 (Ibge, 1991; Bastos et al., 1993; Leal, 2000).

Segundo a classificação de Köeppen, o clima predominante na regiāo é do tipo "Aw", isto é, tropical chuvoso com estação seca bem definida, caracterizado por temperatura média anual de $27,2^{\circ} \mathrm{C}$, com umidade relativa do ar de $81 \%$ e precipitaçáo pluviométrica média de $1766 \mathrm{~mm} / \mathrm{ano}$. O período de menor disponibilidade hídrica ocorre de julho a outubro (Watrin e Rocha, 1992).

A área apresenta uma topografia que vai de plana a suavemente ondulada, sendo identificada como pertencente à Região Geomorfológica Planalto Setentrional Pará-Maranhão (Brasil, 1973). O município é drenado por duas bacias, a do rio Capim e a do rio Gurupi, servindo este último de divisa com o Estado do Maranhão (Watrin e Rocha, 1992).

As principais classes de solos, identificados por Silva (1997) na região, são: Latossolo Amarelo, Podzólico Amarelo, Glei Pouco Húmico, além dos Argissolos encontrados por Brasil (1973; 1974).

A vegetaçáo da área estudada foi classificada e caracterizada de acordo com Veloso et al. (1991), nos seguintes ambientes fitoecológicos: floresta ombrófila densa, também conhecida como floresta equatorial úmida de terra firme; floresta ombrófila aberta mista de cipó e palmeira; e floresta ombrófila densa aluvial, conhecida também como floresta equatorial úmida de várzea.

A pesquisa foi realizada na Unidade de Trabalho No 2 (UT 2), com 108ha, na Unidade de Produção Anual No 7 (UPA 7) da Unidade de Manejo Florestal da Fazenda Rio Capim. Foram realizadas duas mediçōes: a primeira, em 2003, antes da exploração florestal, a segunda, em 2004, após a exploração.

Foram estabelecidos dois tratamentos $\left(\mathrm{T}_{1}\right.$ e $\left.\mathrm{T}_{2}\right)$, tendo como base a intensidade de colheita de madeira, e uma testemunha $\left(\mathrm{T}_{0}\right)$ para o acompanhamento da floresta nãoexplorada. O Tratamento $1\left(\mathrm{~T}_{1}\right)$ consistiu na exploraçáo de impacto reduzido com a retirada apenas dos fustes das árvores comerciais e o Tratamento $2\left(\mathrm{~T}_{2}\right)$ na exploração de impacto reduzido com a retirada dos fustes das árvores comerciais mais a retirada dos resíduos lenhosos (galhos, restos de troncos, árvores tombadas durante a derruba, partes de troncos não aproveitáveis durante o traçamento).

A exploração foi realizada igualmente em toda a área, com exceção das amostras-testemunha, seguindo as diretrizes estabelecidas no plano de manejo da empresa. Após a exploração, foram retirados os resíduos das parcelas sorteadas para o tratamento dois $\left(T_{2}\right)$. Foram exploradas, em média, 4,33 árvores/ha de 17 espécies comerciais.

Para o monitoramento da vegetaçáo nos 108ha, foram estabelecidas, aleatoriamente, 36 parcelas quadradas de 0,25 ha sendo: doze para estudar a floresta não-explorada, doze para a área explorada com retirada apenas do fuste comercial das árvores e doze para a área explorada com retirada do fuste comercial e retirada do resíduo lenhoso.

A metodologia para a realização do inventário florestal contínuo foi a sugerida por Silva e Lopes (1984), revisada 
e atualizada por Silva et al. (2005). Assim cada parcela de 0,25 ha foi dividida em 25 subparcelas de $10 \mathrm{~m} \times 10 \mathrm{~m}$, onde foram registrados e avaliados todos os indivíduos arbóreos $(\mathrm{DAP} \geq 10 \mathrm{~cm})$.

Nas árvores com fuste normal e sem sapopemas, o diâmetro foi medido a $1,30 \mathrm{~m}$ do solo. Nas árvores com sapopemas, nós, calosidades, podridão, danos ou qualquer deformação a $1,30 \mathrm{~m}$, a medição foi feita em outra posição no fuste, sem influência dessas irregularidades.

Os procedimentos para medição e registro dos dados das parcelas permanentes foram aqueles estabelecidos nas diretrizes propostas por Silva et al. (2005).

A identificação dos indivíduos foi realizada, na floresta por parabotânicos da Embrapa Amazônia Oriental e da empresa Cikel Brasil Verde Madeiras Ltda., usando o nome popular como referência. Foi coletado material botânico das espécies menos comuns e dos grupos de espécies que suscitaram dúvidas, para a identificação através da comparação, no Herbário IAN da Embrapa Amazônia Oriental.

Este trabalho teve como base os aspectos metodológicos levados em consideração por Lamprecht (1964) e Finol U. (1971), para a avaliaçáo dos parâmetros fitossociológicos. A abundância foi considerada como sendo o número total de indivíduos de cada espécie que ocorreu na amostragem, por unidade de área. A freqüência foi determinada pela relaçấo entre o número de sub-parcelas em que ocorreu uma determinada espécie e o número total de sub-parcelas. A dominância foi determinada pela somatória das áreas transversais de todos os indivíduos de uma dada espécie. $\mathrm{O}$ índice de valor de importância (IVI) foi determinado pela somatória dos valores relativos de abundância, freqüência e dominância.

No processamento dos dados foi utilizado o programa MFT (Monitoramento de Florestas Tropicais), desenvolvido pela Embrapa Amazônia Oriental, que tem por objetivo analisar os parâmetros referentes à florística e à estrutura da floresta; e na avaliação estatística do estudo foi utilizado o BioEstat 4.0 (Ayres et al., 2005).

Analisou-se a estrutura da floresta em duas ocasiōes (2003 - antes da exploração; e 2004 - após a exploração) com base na abundância, freqüência e área basal das espécies arbóreas.

\section{RESULTADOS E DISCUSSÃO}

Em 2003, antes da exploração florestal, foram registrados 4469 indivíduos com $D A P \geq 10 \mathrm{~cm}$, nas 36 parcelas amostradas (9ha). Sete meses após a exploração (2004), foram registrados 4531 indivíduos com DAP $\geq 10 \mathrm{~cm}$, sendo 4330 vivos.

\section{ABUNDÂNCIA DAS ESPÉCIES}

$\mathrm{Na}$ medição realizada antes da exploração (2003) foram registrados 496,34 indivíduos/ha. O teste t para amostras independentes entre os pares dos tratamentos $\left(\mathrm{T}_{0}\right.$ e $\mathrm{T}_{1} ; \mathrm{T}_{0}$ e $\mathrm{T}_{2} ; \mathrm{T}_{1}$ e $\mathrm{T}_{2}$ ) antes da exploraçáo florestal demonstrou que não houve diferença significativa entre as médias em relação à abundância de espécies a $95 \%$ de probabilidade.

Maciel et al. (2000), analisando a estrutura de uma área de 51 ha de floresta de terra firme em Caxiuană, encontraram 135,78 árvores/ha, considerando os indivíduos com DAP $\geq$ $25 \mathrm{~cm}$. Jardim e Hosokawa (1986/87) ao analisarem indivíduos com DAP $\geq 20 \mathrm{~cm}$ identificaram 246,75 árvores/ha, em uma área de 8 ha de floresta de terra firme, às proximidades de Manaus. Nesses dois estudos a abundância de árvores foi inferior à encontrada na Fazenda Rio Capim, contudo, não foram considerados os indivíduos das classes diamétricas inferiores (10 a $24 \mathrm{~cm}$ no primeiro estudo e 10 a $19 \mathrm{~cm}$ no segundo). Entretanto, Amaral et al. (2000), ao estudarem os indivíduos com $\mathrm{DAP} \geq 10 \mathrm{~cm}$ em uma área de um hectare de floresta densa de terra firme no Rio Uatumã (AM), encontraram uma abundância de 741 indivíduos/ha, por conseguinte maior que o valor encontrado no presente estudo (Fazenda Rio Capim).

Em 2004, após a exploração foram registrados 480,92 indivíduos/ha $(\mathrm{DAP} \geq 10 \mathrm{~cm})$, indicando que a colheita de madeira reduziu o número de indivíduos vivos na área em 3,2\% em relação ao registrado antes da exploração. $\mathrm{O}$ número de indivíduos mortos (201) foi superior ao número de ingressos (62 indivíduos). Este resultado pode ser explicado em função do curto espaço de tempo entre as medições.

Nos resultados do teste $\mathrm{t}$ para amostras pareadas entre as duas mediçôes foi observada diferença significativa ao nível de $95 \%$ de probabilidade, para a variável abundância, entre os tratamentos em que foi realizada a exploraçáo florestal ( $T_{1}(2003)$ e $T_{1}(2004) ; T_{2}(2003)$ e $T_{2}(2004)$ ). Realizado o teste t para amostras independentes, após a exploração, não foi detectada qualquer diferença significativa entre os pares de tratamentos $\left(\mathrm{T}_{0}\right.$ e $\left.\mathrm{T}_{1}\right),\left(\mathrm{T}_{0}\right.$ e $\left.\mathrm{T}_{2}\right)$ e $\left(\mathrm{T}_{1}\right.$ e $\left.\mathrm{T}_{2}\right)$.

Houve um acréscimo de $0,81 \%$ na abundância total da testemunha $\left(\mathrm{T}_{0}\right)$, da primeira (2003) para a segunda (2004) medição. Nas áreas em que foram aplicados os tratamentos $\mathrm{T}_{1}$ e $\mathrm{T}_{2}$, no entanto, foi observada a reduçâo na abundância. Apesar da mortalidade no $\mathrm{T}_{1}$ (apenas colheita dos fustes) ter sido inferior a do $\mathrm{T}_{2}$ (colheita do fuste + retirada de resíduos), foi observado que o decréscimo na abundância foi maior nas parcelas do $\mathrm{T}_{1}(5,18 \%)$, quando comparadas ao $\mathrm{T}_{2}(4,85 \%)$, o que pode ser explicado pelo maior número de ingressos no $T_{2}$ (30 indivíduos) do que no $T_{1}$, que apresentou 11 indivíduos novos. 
O maior número de indivíduos novos nas parcelas em que foi aplicado o tratamento $T_{2}$ pode ter ocorrido pela abertura ocasionada pela exploraçáo somada à atividade de retirada de resíduos favorecendo, deste modo, o crescimento e ingresso desses indivíduos.

Gomide (1997), analisando a estrutura de uma floresta primária no estado do Amapá, em um período de 11 anos, verificou um acréscimo de $3 \%$ na abundância, enquanto Carvalho (1992), ao estudar uma área de floresta nãoexplorada, na Floresta Nacional do Tapajós, em um período de seis anos, percebeu um acréscimo de $0,6 \%$ no número de indivíduos. Nas parcelas-testemunhas $\left(\mathrm{T}_{0}\right)$ do presente estudo, em um período de sete meses, o acréscimo foi de $0,8 \%$ no número de indivíduos, superior ao acréscimo verificado por Carvalho (1992) em seis anos.

Os resultados deste trabalho diferiram dos encontrados por Carvalho (1992), que, ao avaliar a abundância de uma floresta um ano após a colheita dos indivíduos com DAP $\geq 45 \mathrm{~cm}$, observou um decréscimo de $16 \%$ em relação à abundância inicial. Entretanto, naquele trabalho foram colhidas 14 árvores/ha enquanto no presente estudo esse número foi de apenas 4,33 árvores/ha. Assim, o número de árvores mortas em conseqüência da exploração foi bem maior naquele trabalho.

No estudo de Vidal et al. (1998), comparando os efeitos da exploraçáo madeireira predatória com os da planejada em uma fazenda localizada no município de Paragominas - PA, foi observado, que na área explorada de forma planejada houve redução de $16 \%$ no número de indivíduos, logo após a exploração, aumentando para $20 \%$ aos três anos após o corte. $\mathrm{Na}$ área em que foi realizada a exploração predatória, essa redução foi maior, sendo de $20 \%$ logo após a colheita e $25 \%$ três anos depois.

$\mathrm{Na}$ Tabela 1 estão relacionadas as dez espécies mais abundantes em cada tratamento, antes (2003) e após (2004) a exploração florestal.
A espécie mais abundante na área não-explorada (testemunha) e no $\mathrm{T}_{1}$ (colheita apenas dos fustes) foi Rinorea flavescens, seguida de Lecythis idatimon e Poecilanthe effusa, tanto antes quanto após a exploração. $\mathrm{No}_{2}$, Rinorea flavescens ocupa o terceiro lugar, ficando em primeiro e segundo lugares as espécies Lecythis idatimon e Poecilanthe effusa, respectivamente. Essas três espécies estáo representadas apenas nas classes inferiores a $40 \mathrm{~cm}$. Sandel e Carvalho (2000), ao estudarem a composição florística e a estrutura em uma área de floresta localizada na FLONA Tapajós, verificaram que Rinorea flavescens, também, foi a espécie que apresentou maior abundância, com 12,90\% em relação às demais espécies. Entretanto, Rinorea flavescens não ocorreu entre as mais abundantes no estudo realizado por Maciel et al. (2000) em uma floresta de terra firme em Caxiuanã, onde foi superada por Pouteria spp., Eschweilera parviflora, Vouacapoua americana, Geissospermum sericeum, Ocotea myriantha, Parkia auriculata, Licania spp., Licania heteromorpha, Inga spp. e Manilkara amazonica. Isto confirma as afirmativas de Richards (1996) de que em cada localidade há um conjunto característico de espécies dominantes.

Gomide (1997), verificou que a espécie mais abundante em uma floresta primária no Amapá foi Eschweilera coriaceae (DAP $\geq 5 \mathrm{~cm}$ ) com 66 indivíduos/ha $(5,09 \%)$, seguida por Eschweilera subglandulosa com 55 indivíduos/ha (4,24\%), Rinorea guianensis com 54 indivíduos/ha (4,16\%), Protium opacum e Eschweilera amazonica ambas com 31 indivíduos/ha e 2,39\%. No presente estudo, porém, as espécies Eschweilera coriacea (9 indivíduos/ha), Rinorea guianensis ( 0,67 indivíduo/ ha) e Eschweilera amazonica (0,33 indivíduo/ha) ocuparam o $10^{\circ}, 134^{\circ}$ e $158^{\circ}$ lugares, respectivamente, nas parcelastestemunhas ( $2^{\text {a }}$ medição), enquanto Eschweilera subglandulosa e Protium opacum não ocorreram na área.

$\mathrm{Na}$ floresta secundária que cresceu após o corte raso, observou-se, um ano após o corte, que as espécies mais abundantes eram Cecropia sciadophylla (375,5 indivíduos/

Tabela 1 - Abundância absoluta (A) e relativa (AR) das dez espécies mais abundantes, em cada tratamento, em 108ha (amostra de 3ha por tratamento) de floresta natural na Fazenda Rio Capim, Paragominas, PA, considerando árvores com DAP $\geq 10 \mathrm{~cm}$.

\begin{tabular}{|c|c|c|c|c|c|}
\hline \multirow{2}{*}{ Nome científico } & \multicolumn{2}{|c|}{$\mathrm{T}_{0}(2003)$} & \multirow{2}{*}{ Nome científico } & \multicolumn{2}{|c|}{$\mathrm{T}_{0}(2004)$} \\
\hline & $A(n / h a)$ & AR $(\%)$ & & $A(n / h a)$ & $A R(\%)$ \\
\hline Rinorea flavescens & 40,33 & 8,20 & Rinorea flavescens & 41,67 & 8,41 \\
\hline Lecythis idatimon & 37,67 & 7,66 & Lecythis idatimon & 37,67 & 7,60 \\
\hline Poecilanthe effusa & 35,33 & 7,19 & Poecilanthe effusa & 36,00 & 7,27 \\
\hline Eschweilera grandiflora & 25,67 & 5,22 & Eschweilera grandiflora & 26,00 & 5,25 \\
\hline Eschweilera pedicellata & 21,33 & 4,34 & Eschweilera pedicellata & 21,67 & 4,37 \\
\hline Inga sp. & 19,33 & 3,93 & Inga sp. & 19,33 & 3,90 \\
\hline Vouacapoua americana & 10,33 & 2,10 & Vouacapoua americana & 10,33 & 2,09 \\
\hline Pouteria decorticans & 10,00 & 2,03 & Pouteria decorticans & 10,33 & 2,09 \\
\hline Protium spp. & 10,00 & 2,03 & Protium spp. & 10,33 & 2,09 \\
\hline Eschweilera coriacea & 9,00 & 1,83 & Eschweilera coriácea & 9,00 & 1,82 \\
\hline TOTAL & 218,99 & 44,53 & & 222,33 & 44,89 \\
\hline
\end{tabular}




\begin{tabular}{|c|c|c|c|c|c|}
\hline \multirow{2}{*}{ Nome científico } & \multicolumn{2}{|c|}{$\mathrm{T}_{1}(2003)$} & \multirow{2}{*}{ Nome científico } & \multicolumn{2}{|c|}{$T_{1}(2004)$} \\
\hline & $A(n / h a)$ & $A R(\%)$ & & $\mathrm{A}(\mathrm{n} / \mathrm{ha})$ & $A R(\%)$ \\
\hline Rinorea flavescens & 36,67 & 7,60 & Rinorea flavescens & 35,67 & 7,79 \\
\hline Lecythis idatimon & 35,67 & 7,39 & Lecythis idatimon & 33,67 & 7,36 \\
\hline Poecilanthe effusa & 33,67 & 6,98 & Poecilanthe effusa & 32,67 & 7,14 \\
\hline Eschweilera pedicellata & 24,33 & 5,04 & Eschweilera pedicellata & 24,33 & 5,32 \\
\hline Eschweilera grandiflora & 22,00 & 4,56 & Eschweilera grandiflora & 21,00 & 4,59 \\
\hline Inga sp. & 19,33 & 4,01 & Inga sp. & 19,00 & 4,15 \\
\hline Protium spp. & 11,67 & 2,42 & Protium spp. & 11,33 & 2,48 \\
\hline Guatteria poeppigiana & 11,33 & 2,35 & Guatteria poeppigiana & 9,67 & 2,11 \\
\hline Pouteria oppositifolia & 9,33 & 1,93 & Pouteria oppositifolia & 8,67 & 1,89 \\
\hline Vouacapoua americana & 8,67 & 1,80 & Pouteria macrocarpa & 8,33 & 1,82 \\
\hline TOTAL & 212,67 & 44,08 & & 204,34 & 44,65 \\
\hline \multirow{2}{*}{ Nome científico } & \multicolumn{2}{|c|}{$\mathrm{T}_{2}(2003)$} & Nome científico & \multicolumn{2}{|c|}{$\mathrm{T}_{2}(2004)$} \\
\hline & $A(n / h a)$ & AR (\%) & Nome cientunco & $\mathrm{A}(\mathrm{n} / \mathrm{ha})$ & AR (\%) \\
\hline Lecythis idatimon & 46,67 & 9,06 & Lecythis idatimon & 41,67 & 8,50 \\
\hline Poecilanthe effusa & 41,00 & 7,96 & Poecilanthe effusa & 38,67 & 7,89 \\
\hline Rinorea flavescens & 36,33 & 7,05 & Rinorea flavescens & 34,33 & 7,00 \\
\hline Eschweilera grandiflora & 27,67 & 5,37 & Eschweilera grandiflora & 27,00 & 5,51 \\
\hline Eschweilera pedicellata & 24,67 & 4,79 & Eschweilera pedicellata & 24,33 & 4,96 \\
\hline Inga sp. & 21,67 & 4,20 & Inga sp. & 22,00 & 4,49 \\
\hline Guatteria poeppigiana & 18,67 & 3,62 & Guatteria poeppigiana & 17,33 & 3,54 \\
\hline Protium spp. & 15,00 & 2,91 & Protium spp. & 14,33 & 2,92 \\
\hline Vouacapoua americana & 10,67 & 2,07 & Vouacapoua americana & 10,33 & 2,11 \\
\hline Pouteria oppositifolia & 8,00 & 1,55 & Pouteria macrocarpa & 8,00 & 1,63 \\
\hline TOTAL & 250,35 & 48,58 & & 237,99 & 48,55 \\
\hline
\end{tabular}

$T_{0}$ - Floresta não-explorada; $T_{1}$ - Colheita apenas dos fustes; $T_{2}$ - Colheita dos fustes + retirada de resíduos lenhosos; 2003 - Primeira medição (antes da exploração); 2004 Segunda medição (após a exploração).

ha) e Cecropia obtusa (265,5 indivíduos/ha), isto é, espécies pioneiras que foram favorecidas pelas grandes aberturas (Gomide, 1997). No presente estudo, as espécies do gênero Cecropia, após a exploração, ocorreram com baixa abundância, pois a exploração realizada de forma planejada provocou apenas pequenas aberturas no dossel florestal, não permitindo a infestação por espécies invasoras e o intervalo de tempo de medição não foi suficiente para que as plantas desta espécie atingissem o diâmetro mínimo de medição de $10 \mathrm{~cm}$.

Nas parcelas não-exploradas, as alterações em abundância de espécies foram mínimas, ocorrendo, inclusive, um pequeno acréscimo no número total de indivíduos na segunda medição, em relação à primeira. Nas parcelas exploradas foi observada a redução na abundância de algumas espécies, como conseqüência da exploração. Por exemplo, Vouacapona americana (acapu) e Pouteria oppositifolia (abiu-rosadinho), que antes da exploração (2003) estavam entre as dez mais abundantes em $\mathrm{T}_{1}$ e $\mathrm{T}_{2}$, respectivamente, após a exploração perderam o lugar para Pouteria macrocarpa (abiu), que nem estava entre as dez espécies mais abundantes antes da exploração. Em $\mathrm{T}_{1}$ este fato ocorreu devido a morte de dois indivíduos de $V$. americana e a permanência do mesmo número de indivíduos de Pouteria macrocarpa (25 indivíduos antes e após a exploração). Em $\mathrm{T}_{2}$, houve a morte de três indivíduos de P. oppositifolia e o ingresso de um indivíduo de P. macrocarpa.

\section{FREQÜÊNCIA DAS ESPÉCIES}

A espécie melhor distribuída antes da exploração florestal (2003), em toda a amostra, foi Lecythis idatimon, que esteve presente em $32,67 \%$ das subparcelas amostradas com freqüência relativa de $7,19 \%$. Foi seguida pelas espécies Rinorea flavescens que ocorreu em $31,44 \%$ das subparcelas, Poecilanthe effusa em 30,00\% e Eschweilera grandiflora com freqüência de $21,56 \%$. Essas quatro espécies, embora não tenham ocorrido nas 900 subparcelas amostradas, estiveram presentes em todas as 36 parcelas amostradas.

Barros et al. (2000), ao analisarem a fitossociologia de uma floresta situada em Curuá-Una verificaram que Tetragastris panamensis foi à única espécie que ocorreu em todas as unidades amostrais. Maciel et al. (2000) afirmam que Pouteria sp. e Ocotea myriantha foram as espécies com melhor distribuição em floresta de terra firme em Caxiuanã - PA. No presente estudo, Tetragastris panamensis $(\mathrm{F}=1,11 \%)$ e Pouteria sp. $(\mathrm{F}=3,00 \%)$ aparecem na $81^{\mathrm{a}}$ e $35^{\mathrm{a}}$ posiçôes, respectivamente, enquanto Ocotea myriantha nem ocorreu na 
área. Após a exploração, Tetragastris panamensis $(\mathrm{F}=1,11 \%)$ caiu para a $83^{\mathrm{a}}$ posiçáo e Pouteria sp. $(\mathrm{F}=2,33 \%)$ subiu para a $27^{\mathrm{a}}$, demonstrando, portanto, que estas não são as espécies com melhores distribuiçóes na área do presente estudo.

Em 2004 (após a exploraçáo) Lecythis idatimon, Rinorea flavescens, Poecilanthe effusa e Eschweilera grandiflora permaneceram como as mais freqüentes da comunidade, além de serem as mais abundantes.

$\mathrm{Na}$ Tabela 2 estáo relacionadas as dez espécies melhor distribuídas antes e após a exploraçáo florestal de impacto reduzido. Essas dez espécies foram, também, as mais abundantes.

As espécies mais freqüentes nas duas ocasióes (2003 e 2004) na área não-explorada (testemunha) foram Rinorea flavescens, Lecythis idatimon e Poecilanthe effusa, que foram também as mais abundantes. Essas também foram as mais freqüentes nas parcelas em que foi realizada a colheita, porém, nesses tratamentos $\left(\mathrm{T}_{1}\right.$ e $\left.\mathrm{T}_{2}\right)$, Lecythis idatimon foi a espécie mais freqüente, enquanto Rinorea flavescens foi mais freqüente na área não-explorada. Rinorea flavescens, também, foi a espécie

Tabela 2 - Freqüência absoluta (F) e relativa (FR) das dez espécies mais freqüentes em cada tratamento, em 108ha (amostra de 3ha por tratamento) de floresta natural na Fazenda Rio Capim, Paragominas, PA, considerando árvores com DAP $\geq 10 \mathrm{~cm}$.

\begin{tabular}{|c|c|c|c|c|c|}
\hline \multirow{2}{*}{ Nome científico } & \multicolumn{2}{|c|}{$\mathrm{T}_{0}(2003)$} & \multirow{2}{*}{ - Nome científico } & \multicolumn{2}{|c|}{$\mathrm{T}_{0}(2004)$} \\
\hline & $\mathrm{F}(\%)$ & FR (\%) & & $\mathrm{F}(\%)$ & FR (\%) \\
\hline Rinorea flavescens & 33,33 & 7,39 & Rinorea flavescens & 34,67 & 7,65 \\
\hline Lecythis idatimon & 30,67 & 6,80 & Lecythis idatimon & 30,67 & 6,77 \\
\hline Poecilanthe effusa & 29,67 & 6,57 & Poecilanthe effusa & 29,67 & 6,55 \\
\hline Eschweilera grandiflora & 21,67 & 4,80 & Eschweilera grandiflora & 22,00 & 4,85 \\
\hline Eschweilera pedicellata & 19,00 & 4,21 & Eschweilera pedicellata & 19,00 & 4,19 \\
\hline Inga sp. & 15,33 & 3,40 & Inga sp. & 15,33 & 3,38 \\
\hline Protium spp. & 10,00 & 2,22 & Protium spp. & 10,33 & 2,28 \\
\hline Vouacapoua americana & 10,00 & 2,22 & Vouacapoua americana & 10,00 & 2,21 \\
\hline Pouteria decorticans & 9,67 & 2,14 & Pouteria decorticans & 10,00 & 2,21 \\
\hline Pouteria cladantha & 8,67 & 1,92 & Pouteria cladantha & 8,67 & 1,91 \\
\hline TOTAL & -- & 41,67 & & --- & 42,00 \\
\hline \multirow{2}{*}{ Nome científico } & \multicolumn{2}{|c|}{$T_{1}(2003)$} & \multirow{2}{*}{ Nome científico } & \multicolumn{2}{|c|}{$\mathrm{T}_{1}(2004)$} \\
\hline & $\mathrm{F}(\%)$ & FR (\%) & & $\mathrm{F}(\%)$ & FR (\%) \\
\hline Lecythis idatimon & 30,33 & 6,88 & Lecythis idatimon & 29,00 & 6,95 \\
\hline Rinorea flavescens & 29,00 & 6,58 & Rinorea flavescens & 28,33 & 6,79 \\
\hline Poecilanthe effusa & 28,33 & 6,43 & Poecilanthe effusa & 27,33 & 6,55 \\
\hline Eschweilera pedicellata & 20,33 & 4,62 & Eschweilera pedicellata & 20,00 & 4,79 \\
\hline Eschweilera grandiflora & 19,33 & 4,39 & Eschweilera grandiflora & 18,33 & 4,39 \\
\hline Inga sp. & 16,33 & 3,71 & Inga sp. & 15,67 & 3,75 \\
\hline Protium spp. & 10,67 & 2,42 & Protium spp. & 10,33 & 2,48 \\
\hline Guatteria poeppigiana & 10,33 & 2,35 & Guatteria poeppigiana & 9,00 & 2,16 \\
\hline Pouteria oppositifolia & 8,67 & 1,97 & Pouteria oppositifolia & 8,00 & 1,92 \\
\hline Pouteria macrocarpa & 8,00 & 1,82 & Pouteria macrocarpa & 8,00 & 1,92 \\
\hline TOTAL & --- & 41,17 & & --- & 41,70 \\
\hline \multirow{2}{*}{ Nome científico } & \multicolumn{2}{|c|}{$\mathrm{T}_{2}(2003)$} & - Nome científico & \multicolumn{2}{|c|}{$\mathrm{T}_{2}(2004)$} \\
\hline & $\mathrm{F}(\%)$ & FR (\%) & - Nome clentitico & $\mathrm{F}(\%)$ & FR (\%) \\
\hline Lecythis idatimon & 37,00 & 7,85 & Lecythis idatimon & 33,67 & 7,46 \\
\hline Rinorea flavescens & 32,00 & 6,79 & Rinorea flavescens & 31,00 & 6,87 \\
\hline Poecilanthe effusa & 32,00 & 6,79 & Poecilanthe effusa & 30,00 & 6,65 \\
\hline Eschweilera grandiflora & 23,67 & 5,02 & Eschweilera grandiflora & 23,33 & 5,17 \\
\hline Eschweilera pedicellata & 21,00 & 4,45 & Eschweilera pedicellata & 21,33 & 4,73 \\
\hline Inga sp. & 18,67 & 3,96 & Inga sp. & 18,67 & 4,14 \\
\hline Guatteria poeppigiana & 15,67 & 3,32 & Guatteria poeppigiana & 14,33 & 3,18 \\
\hline Protium spp. & 14,33 & 3,04 & Protium spp. & 13,67 & 3,03 \\
\hline Vouacapoua americana & 10,00 & 2,12 & Vouacapoua americana & 10,00 & 2,22 \\
\hline Pouteria oppositifolia & 7,67 & 1,63 & Pouteria macrocarpa & 7,67 & 1,70 \\
\hline TOTAL & --- & 44,97 & & --- & 45,15 \\
\hline
\end{tabular}

T - Floresta não-explorada; $T_{1}$ - Colheita apenas dos fustes; $T_{2}$ - Colheita dos fustes + retirada de resíduos lenhosos; 2003 - Primeira medição (antes da exploração); 2004 Segunda medição (após a exploração). 
com maior freqüência em uma área de cinco hectares de mata alta sem babaçu na FLONA Tapajós com freqüência relativa de 7,77\% (Sandel e Carvalho, 2000).

A espécie Pouteria oppositifolia (abiu-rosadinho), que antes da exploraçáo ocorria entre as dez mais freqüentes no tratamento 2 (colheita + resíduos), após a exploraçáo, perdeu a posição para Pouteria macrocarpa (abiu), pelo fato de Pouteria oppositifolia deixar de ocorrer (mortalidade) em três subparcelas e de Pouteria macrocarpa ocorrer (ingresso) em uma subparcela a mais na segunda medição.

Das espécies mais freqüentes no estudo de Maciel $e t$ al. (2000), na Floresta Nacional de Caxiuanã, apenas as espécies Inga sp. e Vouacapoua americana foram registradas no presente estudo, também, com alta freqüência. Inga sp. está entre as dez mais freqüentes do povoamento $\left(\mathrm{T}_{0}, \mathrm{~T}_{1} \mathrm{e} \mathrm{T}_{2}\right)$. Vouacapoua americana está entre as mais freqüentes na área não-explorada $\left(\mathrm{T}_{0}\right)$ e na área com colheita dos fustes mais a retirada dos resíduos $\left(\mathrm{T}_{2}\right)$.

\section{DOMINÂNCIA DAS ESPÉCIES}

A área basal média da floresta, antes da exploração florestal, foi de $26,78 \mathrm{~m}^{2} /$ ha, com $26,52 \mathrm{~m}^{2} / \mathrm{ha}$ em $\mathrm{T}_{0}, 27,11 \mathrm{~m}^{2} / \mathrm{ha}$ em $T_{1}$ e $27,00 \mathrm{~m}^{2} /$ ha em $T_{2}$. Os resultados do teste t para amostras independentes entre os tratamentos $\left(\mathrm{T}_{0} \mathrm{e} \mathrm{T}_{1} ; \mathrm{T}_{0} \mathrm{e}\right.$ $\mathrm{T}_{2} ; \mathrm{T}_{1} \mathrm{e} \mathrm{T}_{2}$ ) indicaram que não há diferença significativa entre as médias da área basal dos tratamentos, ao nível de 95\% de probabilidade.

A área basal da presente floresta estudada é semelhante à área de outras florestas na Amazônia. Jardim e Hosokawa (1986/1987), ao analisarem indivíduos com DAP $\geq 20 \mathrm{~cm}$ nas proximidades de Manaus, verificaram uma área basal de $25,00 \mathrm{~m}^{2} / \mathrm{ha}$. Maciel et al. (2000) encontraram $23,00 \mathrm{~m}^{2} / \mathrm{ha}$ para árvores com DAP $\geq 25 \mathrm{~cm}$ em Caxiuanã. No presente estudo, considerando indivíduos com DAP $\geq 20 \mathrm{~cm}$, a área basal é de $22,10 \mathrm{~m}^{2} / \mathrm{ha}$, entretanto, inferior aos estudos citados.
Gomide (1997), estudando uma área de floresta primária no estado do Amapá e Carvalho (1992), em uma área na Flona Tapajós, registraram área basal média de $35,60 \mathrm{~m}^{2} / \mathrm{ha} \mathrm{e}$ $31,11 \mathrm{~m}^{2} / \mathrm{ha}$, respectivamente, mas consideraram indivíduos com DAP $\geq 5 \mathrm{~cm}$.

A exploraçáo florestal ocasionou a redução de $5,6 \%$ na área basal total da floresta em estudo, resultando em $25,27 \mathrm{~m}^{2} /$ ha $\left(T_{0}=26,53 \mathrm{~m}^{2} / \mathrm{ha} ; \mathrm{T}_{1}=25,06 \mathrm{~m}^{2} / \mathrm{ha} ; \mathrm{T}_{2}=24,26 \mathrm{~m}^{2} / \mathrm{ha}\right)$. Foi verificado que há um ligeiro acréscimo nas parcelastestemunhas $\left(0,01 \mathrm{~m}^{2} / \mathrm{ha}\right)$ e uma reduçáo de 2,04 e $2,74 \mathrm{~m}^{2} /$ ha nas parcelas em que foram aplicados os tratamentos $\mathrm{T}_{1} \mathrm{e}$ $\mathrm{T}_{2}$, respectivamente. Esta redução foi causada pela colheita de árvores de grande porte e pela mortalidade de outras árvores ocasionada pela derruba e arraste. Contudo, nos resultados do teste $t$ para amostras independentes entre os tratamentos $\left(T_{0}\right.$ e $\mathrm{T}_{1} ; \mathrm{T}_{0} \mathrm{e} \mathrm{T}_{2} ; \mathrm{T}_{1} \mathrm{e} \mathrm{T}_{2}$ ), mesmo após a exploração florestal, não foi observada diferença significativa a $95 \%$ de probabilidade, devido ao fato da variaçáo entre eles ser pequena. Entretanto, nas amostras pareadas entre as duas mediçôes, houve diferença significativa para os tratamentos $\mathrm{T}_{1}\left(2003\right.$ e 2004) e $\mathrm{T}_{2}(2003$ e 2004), devido à extraçấo de árvores de grande porte nos diferentes tratamentos.

As espécies Manilkara paraensis (maparajuba) e Manilkara huberi (maçaranduba), que antes da exploração estavam entre as dez mais dominantes da amostra $\left(\mathrm{T}_{0}+\mathrm{T}_{1}+\mathrm{T}_{2}\right)$, após a exploração perderam o lugar para Inga sp. e Pouteria oppositifolia (abiu-rosadinho), devido à colheita de seis indivíduos de grande porte (três de maparajuba e três de maçaranduba $\left.\left(T_{1}+T_{2}\right)\right)$.

As espécies dominantes antes e após a exploração florestal em cada tratamento estáo relacionadas na Tabela 3.

Eschweilera grandiflora foi a espécie de maior dominância, tanto antes como após a exploração florestal, nas parcelastestemunhas e nas parcelas onde apenas os fustes das árvores foram colhidos. Em seguida estâo as espécies Lecythis idatimon e Vouacapoua americana.

Tabela 3 - Dominância absoluta (D) e relativa (DR) das dez espécies com maior área basal, em cada tratamento, em 108ha (amostra de 3ha por tratamento) de floresta natural na Fazenda Rio Capim, Paragominas, PA, considerando árvores com DAP $\geq 10 \mathrm{~cm}$.

\begin{tabular}{lcclcc}
\multirow{2}{*}{ Nome científico } & \multicolumn{2}{c}{$\mathrm{T}_{0}(2003)$} & \multicolumn{2}{c}{$\mathrm{T}_{0}(2004)$} \\
\cline { 2 - 3 } & $\mathrm{D}\left(\mathrm{m}^{2} \mathrm{ha}\right)$ & $\mathrm{DR}(\%)$ & & $\mathrm{D}\left(\mathrm{m}^{2} / \mathrm{ha}\right)$ & $\mathrm{DR}(\%)$ \\
\hline Eschweilera grandiflora & 1,31 & 4,94 & Eschweilera grandiflora & 1,34 & 5,03 \\
Lecythis idatimon & 1,25 & 4,71 & Lecythis idatimon & 1,22 & 4,59 \\
Vouacapoua americana & 0,97 & 3,65 & Vouacapoua americana & 0,99 & 3,72 \\
Manilkara paraensis & 0,84 & 3,16 & Manilkara paraensis & 0,86 & 3,23 \\
Eschweilera coriacea & 0,80 & 3,00 & Eschweilera coriacea & 0,80 & 3,03 \\
Eschweilera pedicellata & 0,67 & 2,51 & Eschweilera pedicellata & 0,77 & 2,89 \\
Pouteria elegans & 0,64 & 2,42 & Pseudopiptadenia suaveolens & 0,62 & 2,35 \\
Pseudopiptadenia suaveolens & 0,61 & 2,30 & Pouteria elegans & 0,65 & 2,44 \\
Ecclinusa guianensis & 0,60 & 2,25 & Ecclinusa guianensis & 0,60 & 2,26 \\
Inga sp. & 0,56 & 2,12 & Poecilanthe effusa & 0,58 & 2,19 \\
TOTAL & 8,25 & 31,06 & & 8,43 & 31,73 \\
\hline
\end{tabular}




\begin{tabular}{|c|c|c|c|c|c|}
\hline \multirow{2}{*}{ Nome científico } & \multicolumn{2}{|c|}{$\mathrm{T}_{1}(2003)$} & \multirow{2}{*}{ Nome científico } & \multicolumn{2}{|c|}{$T_{1}(2004)$} \\
\hline & $\mathrm{D}\left(\mathrm{m}^{2} / \mathrm{ha}\right)$ & $\mathrm{DR}(\%)$ & & $\mathrm{D}\left(\mathrm{m}^{2} / \mathrm{ha}\right)$ & DR (\%) \\
\hline Eschweilera grandiflora & 1,26 & 4,65 & Eschweilera grandiflora & 1,24 & 4,96 \\
\hline Lecythis idatimon & 1,17 & 4,29 & Lecythis idatimon & 1,11 & 4,42 \\
\hline Vouacapoua americana & 1,13 & 4,18 & Vouacapoua americana & 1,02 & 4,08 \\
\hline Eschweilera pedicellata & 0,96 & 3,54 & Eschweilera pedicellata & 0,96 & 3,84 \\
\hline Manilkara huberi & 0,88 & 3,24 & Pseudopiptadenia suaveolens & 0,71 & 2,84 \\
\hline Pseudopiptadenia suaveolens & 0,86 & 3,16 & Manilkara huberi & 0,68 & 2,71 \\
\hline Pouteria oppositifolia & 0,68 & 2,51 & Pouteria oppositifolia & 0,66 & 2,63 \\
\hline Poecilanthe effusa & 0,65 & 2,41 & Poecilanthe effusa & 0,63 & 2,53 \\
\hline Carapa guianensis & 0,60 & 2,20 & Tachigalia myrmecophyla & 0,62 & 2,47 \\
\hline Brosimum acutifolium & 0,59 & 2,17 & Carapa guianensis & 0,60 & 2,41 \\
\hline TOTAL & 8,78 & 32,35 & & 8,23 & 32,89 \\
\hline \multirow{2}{*}{ Nome científico } & \multicolumn{2}{|c|}{$\mathrm{T}_{2}(2003)$} & Nome cientificn & \multicolumn{2}{|c|}{$\mathrm{T}_{2}(2004)$} \\
\hline & $\mathrm{D}\left(\mathrm{m}^{2} / \mathrm{ha}\right)$ & $\mathrm{DR}(\%)$ & Ivome cientitico & $\mathrm{D}\left(\mathrm{m}^{2} / \mathrm{ha}\right)$ & $\mathrm{DR}(\%)$ \\
\hline Lecythis idatimon & 1,17 & 5,68 & Lecythis idatimon & 1,44 & 5,94 \\
\hline Eschweilera grandiflora & 1,26 & 4,63 & Eschweilera grandiflora & 1,38 & 5,68 \\
\hline Protium spp. & 0,57 & 4,28 & Protium spp. & 1,31 & 5,38 \\
\hline Pseudopiptadenia suaveolens & 0,86 & 4,15 & Pseudopiptadenia suaveolens & 0,85 & 3,50 \\
\hline Vouacapoua americana & 1,13 & 3,34 & Vouacapoua americana & 0,81 & 3,34 \\
\hline Manilkara huberi & 0,88 & 3,12 & Eschweilera pedicellata & 0,72 & 2,99 \\
\hline Manilkara paraensis & 0,35 & 2,90 & Poecilanthe effusa & 0,65 & 2,70 \\
\hline Eschweilera pedicellata & 0,96 & 2,78 & Goupia glabra & 0,63 & 2,58 \\
\hline Poecilanthe effusa & 0,65 & 2,53 & Inga sp. & 0,62 & 2,54 \\
\hline Goupia glabra & 0,36 & 2,28 & Guatteria poeppigiana & 0,59 & 2,42 \\
\hline TOTAL & 8,19 & 35,69 & & 9,00 & 37,07 \\
\hline
\end{tabular}

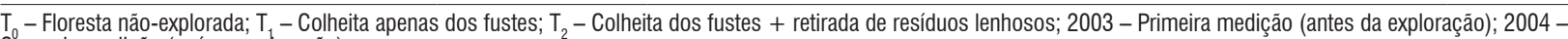
Segunda medição (após a exploração).

Nas parcelas em que foi realizada a colheita dos fustes mais a retirada dos resíduos lenhosos, foi verificado que, tanto antes como após a exploração, as espécies dominantes foram Lecythis idatimon, Eschweilera grandiflora e Protium spp.

Nas parcelas-testemunhas (primeira medição), Inga sp. estava entre as dez dominantes, porém na segunda medição perdeu o lugar para Poecilanthe effusa, devido ao aumento da abundância desta espécie e, conseqüentemente, da área basal.

No Tratamento 1, antes da exploração, Brosimum acutifolium ocorria entre as dez espécies dominantes da área. Após a exploração, essa espécie desceu para a 16a posição, devido à colheita de um indivíduo, permitindo que Tachigalia myrmecophyla subisse para o grupo das dez dominantes.

Manilkara huberi e Manilkara paraensis, antes da exploraçấo florestal, estavam entre as dez espécies dominantes nas parcelas do $\mathrm{T}_{2}$, porém com a colheita de duas árvores, de cada espécie, elas foram substituídas por Inga sp. e Guatteria poeppigiana.

$\mathrm{Na}$ Tabela 4 estão relacionadas as espécies exploradas na UT 2, UPA 7 (área de estudo) e seus respectivos valores absolutos e relativos de abundância, freqüência, dominância e índice de valor de importância (IVI), antes e após a exploração florestal.

Antes da exploração as espécies colhidas representavam $4,55 \%$ da abundância, passando para 3,68\%, porém ocupam juntas 19,44\% e 13,20\% (antes e após a exploração) da área basal existente, mostrando que, apesar de pouco abundantes, estas espécies possuem indivíduos com grandes diâmetros.

Abundância, freqüência e dominância sofreram pequenas alteraçóes com a exploração, pois foram colhidos poucos indivíduos de cada espécie. Apesar dessa redução, esse conjunto de espécies, após a exploraçáo florestal, apresentou distribuição diamétrica contínua, semelhante àquela antes da exploração, com indivíduos, em todas as classes de tamanho (Figura 1). Contudo, ao analisar a distribuição diamétrica de cada espécie, foi observado que algumas apresentaram distribuição irregular, tanto antes como após a exploração, por exemplo, Caryocar villosum (piquiá), Jacaranda copaia (parapará), e Parkia gigantocarpa (fava-atanâ), que apresentaram poucos indivíduos distribuídos de forma descontínua nas classes diamétricas.

As espécies Lecythis pisonis (sapucaia) e Pseudopiptadenia suaveolens (timborana) praticamente não possuem indivíduos nas classes de tamanho inferiores, ao contrário de Brosimum guianense (amapá-amargoso) que tem indivíduos apenas nas 
Tabela 4 - Abundância (A), abundância relativa (AR), dominância (D), dominância relativa (DR), frequêência (F), freqüência relativa (FR) e índice de valor de importância (IVI) das espécies exploradas em 108ha (amostra de 6ha) na UT 02, UPA 07, na Fazenda Rio Capim, Paragominas, PA, considerando árvores com DAP $\geq 10 \mathrm{~cm}$.

\begin{tabular}{|c|c|c|c|c|c|c|c|c|}
\hline \multicolumn{2}{|l|}{ Antes da Exploração } & \multirow{2}{*}{$A(n / h a)$} & \multirow{2}{*}{ AR (\%) } & \multirow{2}{*}{$\mathrm{D}\left(\mathrm{m}^{2} / \mathrm{ha}\right)$} & \multirow{2}{*}{ DR (\%) } & \multirow{2}{*}{$\mathrm{F}(\%)$} & \multirow{2}{*}{$\mathrm{FR}(\%)$} & \multirow{2}{*}{ IVI } \\
\hline Nome científico & Nome comum & & & & & & & \\
\hline Apeiba albiflora & Pente-de-macaco & 3,50 & 0,70 & 0,18 & 0,65 & 3,50 & 0,77 & 2,12 \\
\hline Bombax globosum & Munguba-da-terra-firme & 1,83 & 0,37 & 0,16 & 0,61 & 1,83 & 0,40 & 1,38 \\
\hline Brosimum acutifolium & Mururé & 2,50 & 0,50 & 0,41 & 1,50 & 2,50 & 0,55 & 2,55 \\
\hline Brosimum guianense & Amapá-amargoso & 0,50 & 0,10 & 0,08 & 0,30 & 0,50 & 0,11 & 0,51 \\
\hline Caryocar villosum & Piquiá & 0,33 & 0,07 & 0,07 & 0,25 & 0,33 & 0,07 & 0,39 \\
\hline Copaifera multijuga & Copaíba & 0,17 & 0,03 & 0,02 & 0,06 & 0,17 & 0,04 & 0,13 \\
\hline Couratari sp. & Tauari & 1,67 & 0,33 & 0,37 & 1,36 & 1,50 & 0,33 & 2,02 \\
\hline Euxylophora paraensis & Pau-amarelo & 1,17 & 0,23 & 0,35 & 1,29 & 1,17 & 0,26 & 1,78 \\
\hline Jacaranda copaia & Parapará & 1,17 & 0,23 & 0,17 & 0,61 & 1,00 & 0,22 & 1,06 \\
\hline Laetia procera & Pau-jacaré & 0,67 & 0,13 & 0,20 & 0,73 & 0,67 & 0,15 & 1,01 \\
\hline Lecythis pisonis & Sapucaia & 1,17 & 0,23 & 0,42 & 1,57 & 1,17 & 0,26 & 2,06 \\
\hline Manilkara huberi & Maçaranduba & 1,33 & 0,27 & 0,86 & 3,18 & 1,33 & 0,29 & 3,74 \\
\hline Manilkara paraensis & Maparajuba & 3,50 & 0,70 & 0,56 & 2,08 & 3,50 & 0,77 & 3,55 \\
\hline Parkia gigantocarpa & Fava-atanã & 0,50 & 0,10 & 0,23 & 0,84 & 0,50 & 0,11 & 1,05 \\
\hline Pseudopiptadenia suaveolens & Timborana & 2,17 & 0,43 & 0,99 & 3,65 & 2,17 & 0,47 & 4,55 \\
\hline Simarouba amara & Marupá & 0,17 & 0,03 & 0,09 & 0,35 & 0,17 & 0,04 & 0,42 \\
\hline Swartzia grandifolia & Gombeira-vermelha & 0,50 & 0,10 & 0,11 & 0,41 & 0,50 & 0,11 & 0,62 \\
\hline TOTAL & & 22,85 & 4,55 & 5,27 & 19,44 & --- & 4,95 & 28,94 \\
\hline \multicolumn{2}{|l|}{ Após a Exploração } & \multirow{2}{*}{$A(n / h a)$} & \multirow{2}{*}{ AR (\%) } & \multirow{2}{*}{$\mathrm{D}\left(\mathrm{m}^{2} / \mathrm{ha}\right)$} & \multirow{2}{*}{$\mathrm{DR}(\%)$} & \multirow{2}{*}{$\mathrm{F}(\%)$} & \multirow{2}{*}{$\mathrm{FR}(\%)$} & \multirow{2}{*}{ IVI } \\
\hline Nome científico & Nome comum & & & & & & & \\
\hline Apeiba albiflora & Pente-de-macaco & 3,17 & 0,67 & 0,13 & 0,51 & 3,17 & 0,73 & 1,91 \\
\hline Bombax globosum & Munguba-da-terra-firme & 1,67 & 0,35 & 0,10 & 0,42 & 1,67 & 0,38 & 1,15 \\
\hline Brosimum acutifolium & Mururé & 2,17 & 0,46 & 0,32 & 1,30 & 2,17 & 0,50 & 2,26 \\
\hline Brosimum guianense & Amapá-amargoso & 0,33 & 0,07 & 0,02 & 0,07 & 0,33 & 0,08 & 0,22 \\
\hline Caryocar villosum & Piquiá & 0,17 & 0,04 & 0,01 & 0,03 & 0,17 & 0,04 & 0,11 \\
\hline Copaifera multijuga & Copaíba & 0,00 & 0,00 & 0,00 & 0,00 & 0,00 & 0,00 & 0,00 \\
\hline Couratari sp. & Tauari & 1,33 & 0,28 & 0,19 & 0,77 & 1,17 & 0,27 & 1,32 \\
\hline Euxylophora paraensis & Pau-amarelo & 1,00 & 0,21 & 0,23 & 0,92 & 1,00 & 0,23 & 1,36 \\
\hline Jacaranda copaia & Parapará & 0,83 & 0,18 & 0,13 & 0,51 & 0,83 & 0,19 & 0,88 \\
\hline Laetia procera & Pau-jacaré & 0,17 & 0,04 & 0,02 & 0,09 & 0,17 & 0,04 & 0,17 \\
\hline Lecythis pisonis & Sapucaia & 0,83 & 0,18 & 0,27 & 1,09 & 0,83 & 0,19 & 1,46 \\
\hline Manilkara huberi & Maçaranduba & 0,83 & 0,18 & 0,55 & 2,25 & 0,83 & 0,19 & 2,62 \\
\hline Manilkara paraensis & Maparajuba & 2,50 & 0,53 & 0,31 & 1,25 & 2,50 & 0,58 & 2,36 \\
\hline Parkia gigantocarpa & Fava-atanã & 0,33 & 0,07 & 0,13 & 0,52 & 0,33 & 0,08 & 0,67 \\
\hline Pseudopiptadenia suaveolens & Timborana & 1,67 & 0,35 & 0,78 & 3,16 & 1,67 & 0,38 & 3,89 \\
\hline Simarouba amara & Marupá & 0,00 & 0,00 & 0,00 & 0,00 & 0,00 & 0,00 & 0,00 \\
\hline Swartzia grandifolia & Gombeira-vermelha & 0,33 & 0,07 & 0,08 & 0,31 & 0,33 & 0,08 & 0,46 \\
\hline TOTAL & & 17,33 & 3,68 & 3,27 & 13,20 & --- & 3,96 & 20,84 \\
\hline
\end{tabular}

classes com diâmetro inferior a $40 \mathrm{~cm}$. Simarouba amara (marupá) e Copaifera multijuga (copaíba) devem ser tratadas com mais atenção, tanto em relação à ecologia como à silvicultura, pois nenhum indivíduo dessas duas espécies, com DAP $\geq 10 \mathrm{~cm}$, foi registrado na área após a colheita $\left(T_{1}\right.$ $\left.+\mathrm{T}_{2}\right)$.

\section{ÍNDICE DE VALOR DE IMPORTÂNCIA}

As dez espécies mais importantes na comunidade florestal estudada, antes da exploração, foram Lecythis idatimon, Poecilanthe effusa, Rinorea flavescens, Eschweilera grandiflora, Eschweilera pedicellata, Inga sp., Protium spp., Vouacapoua 


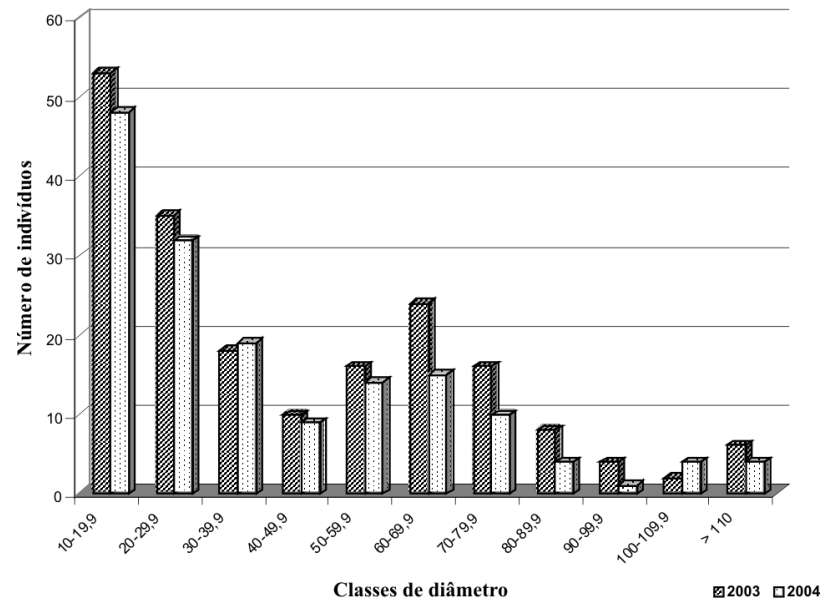

Figura 1 - Distribuição diamétrica das espécies extraídas, considerando árvores com DAP $\geq 10 \mathrm{~cm}$, antes (2003) e após (2004) o processo de exploração florestal, em 108ha (amostra de 6ha) na UT 02, UPA 07 na Fazenda Rio Capim em Paragominas, PA.

americana, Guatteria poeppigiana e Eschweilera coriacea (Figura 2), principalmente, devido à abundância e freqüência.

Lecythis idatimon foi, sem dúvida, a espécie de maior importância e que melhor caracterizou a floresta em estudo, por ser a mais abundante, mais freqüente, e com maior área basal (Figura 2).

Barros et al. (2000), ao analisarem a estrutura considerando indivíduos da classe de $10 \leq \mathrm{DAP}<45 \mathrm{~cm}$ de uma floresta as espécies mais importantes em uma floresta densa de terra firme no estado do Amazonas foram Protium apiculatum e Eschweilera coriacea. Dessas espécies, no presente estudo, antes da exploração $\left(\mathrm{T}_{0}+\mathrm{T}_{1}+\mathrm{T}_{2}\right)$, apenas a espécie Eschweilera coriacea aparece como a $12^{\text {a }}$ espécie de maior importância, as demais ficaram distantes das primeiras colocaçóes. Tetragastris panamensis está na $81^{\text {a }}$ posição, seguida de Rinorea guianensis que ocupa a $83^{\mathrm{a}}$ posição. As demais (Eschweilera sagotiana, Protium sagotianum, Mouriri sp. e Protium apiculatum) não ocorreram na área em estudo, embora alguns indivíduos tenham sido identificados como sendo dos gêneros Protium sp. (196a) e Eschweleira sp. (219a).

Em uma área de terra firme na Floresta Nacional de Caxiuanã, as espécies com maiores índices de valor de importância foram: Pouteria spp., Eschweilera parviflora, Vouacapoua americana, Geissospermum sericeum, Ocotea myriantha, Parkia auriculata, Licania spp., Licania heteromorpha, Inga spp. e Manilkara amazonica (Maciel et al., 2000). No presente estudo, apenas Vouacapoua americana e Inga spp. estão entre as dez mais importantes.

Após a exploração, Pouteria oppositifolia, que teve a sua abundância reduzida, deixou de pertencer ao grupo das dez mais importantes da área $\left(T_{0}+T_{1}+T_{2}\right)$, perdendo o lugar para Eschweilera coriacea que antes não fazia parte deste grupo.

Foi verificada a inversão nas colocações das espécies Guatteria poeppigiana $\left(7^{\mathrm{a}}-9^{\mathrm{a}}\right)$, Protium spp. $\left(8^{\mathrm{a}}-7^{\mathrm{a}}\right)$ e Vouacapoua americana $\left(9^{\mathrm{a}}-8^{\mathrm{a}}\right)$, que sofreram reduçóes em

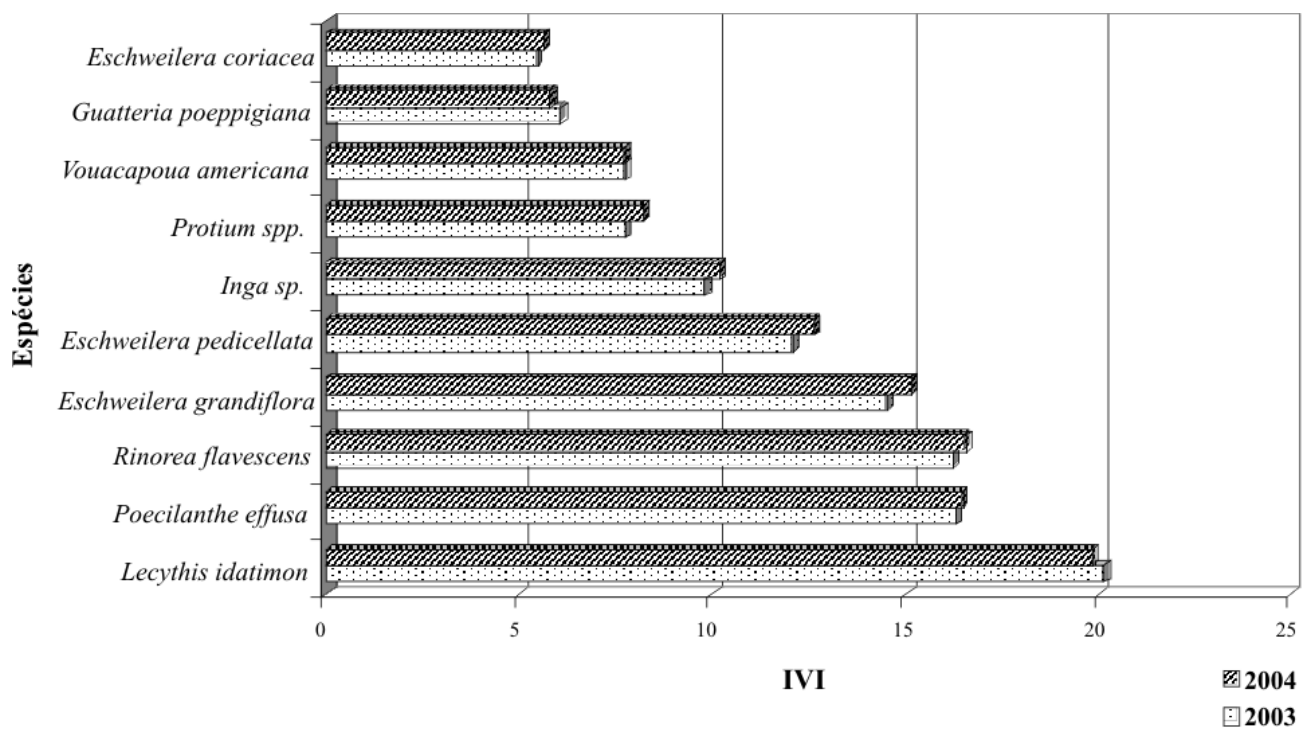

Figura 2 - Mudanças ocorridas no índice de valor de importância (IVI) das dez espécies mais importantes, antes (2003) e depois (2004) da exploração florestal em 108ha (amostra de 9ha) de floresta natural na Fazenda Rio Capim, Paragominas, PA, considerando árvores com DAP $\geq 10 \mathrm{~cm}$.

situada em Curuá-Una, verificaram que Rinorea guianensis, Tetragastris panamensis, Eschweilera sagotiana, Protium sagotianum e Mouriri sp. foram as espécies mais abundantes e com maior IVI na área. Amaral et al. (2000) observaram que abundância, sendo maior em Guatteria poeppigiana, Protium spp. e Vouacapoua americana, no entanto, sofreram reduçóes menores, ganhando, assim, posiçóes em relação a Guatteria poeppigiana. 
Pantoja et al. (1997), ao estudarem a estrutura de uma floresta secundária no Município de Benevides - PA, verificaram que as espécies de maior índice de valor de importância (IVI) foram Vismia guianensis, Emmotum fagifolium, Miconia poeppigiana, Apeiba tibourbou, Byrsonima crispa, Xylopia ovatifolia e Cecropia leucocoma, que juntas representaram 60\% dos IVI's calculados. Dessas espécies, apenas Byrsonima crispa (muruci-da-mata) ocorreu na área do presente estudo, ocupando a $142^{a}$ posição $\left(T_{1}+T_{2}\right)$. Ocorreram, também, os gêneros Miconia sp. e Cecropia sp.

$\mathrm{Na}$ Figura 2 pode ser observado que oito, das dez espécies ecologicamente mais importantes na comunidade, tiveram a sua importância aumentada, após a exploração, devido a uma menor redução no número de indivíduos, quando comparada às demais espécies.

$\mathrm{Na}$ Tabela 5 estão relacionadas as dez espécies mais importantes na estrutura da floresta estudada, antes e após a exploraçáo, considerando os dois tratamentos e a testemunha.

Lecythis idatimon é a espécie de maior importância nos dois tratamentos e na testemunha, devido ao grande número de indivíduos nas classes inferiores de tamanho $(\mathrm{DAP}<40 \mathrm{~cm}$ ), o que também proporcionou maiores valores de área basal.

Resultados diferentes foram obtidos por Miranda (2000) sobre a composição florística e a estrutura da vegetação lenhosa do Rio Comemoraçáo (RO), onde, espécies de terra firme, como Maquira guianensis, Macrolobium acaciefolium e Qualea paraensis ocuparam os primeiros lugares na ordem de importância, devido ao grande porte das árvores dessas espécies, apesar de apresentarem um indivíduo, cada.

Goupia glabra (cupiúba) e Ocotea rubra (louro-gamela) foram às espécies com maiores valores de importância ecológica devido a seus grandes diâmetros, em uma floresta localizada no estado do Amazonas (Matos e Amaral, 1999). No presente estudo, Pseudopiptadenia suaveolens (timborana) está entre as dez espécies com maior importância (antes da exploraçáo florestal) no $T_{2}$, por apresentar indivíduos com grandes diâmetros.

Pouteria cladantha, Pouteria macrocarpa, Pouteria oppositifolia e Pseudopiptadenia suaveolens aparecem entre as dez espécies mais importantes apenas em um tratamento, não aparecendo nos demais.

Tabela 5 - Impacto da exploração florestal no índice de valor de importância (IVI) das dez espécies ecologicamente mais importantes em cada tratamento, em 108ha (amostra de 3ha por tratamento) de floresta natural na Fazenda Rio Capim, Paragominas, PA, considerando árvores com DAP $\geq 10 \mathrm{~cm}$.

\begin{tabular}{|c|c|c|c|}
\hline \multirow{2}{*}{ Nome científico } & \multirow{2}{*}{$\frac{\mathrm{T}_{0}(2003)}{\mathrm{IVI}}$} & \multirow{2}{*}{ - Nome científico } & \multirow{2}{*}{$\frac{\mathrm{T}_{0}(2004)}{\mathrm{IVI}}$} \\
\hline & & & \\
\hline Lecythis idatimon & 19,17 & Lecythis idatimon & 18,96 \\
\hline Rinorea flavescens & 17,57 & Rinorea flavescens & 17,81 \\
\hline Poecilanthe effusa & 15,86 & Poecilanthe effusa & 16,01 \\
\hline Eschweilera grandiflora & 14,96 & Eschweilera grandiflora & 15,13 \\
\hline Eschweilera pedicellata & 11,06 & Eschweilera pedicellata & 11,45 \\
\hline Inga sp. & 9,45 & Inga sp. & 9,42 \\
\hline Vouacapoua americana & 7,97 & Vouacapoua americana & 8,02 \\
\hline Eschweilera coriacea & 6,68 & Eschweilera coriacea & 6,69 \\
\hline Protium spp. & 6,09 & Protium spp. & 6,25 \\
\hline Pouteria cladantha & 5,59 & Pouteria cladantha & 5,62 \\
\hline TOTAL & 114,4 & & 115,3 \\
\hline \multirow{2}{*}{ Nome científico } & $\mathrm{T}_{1}(2003)$ & \multirow{2}{*}{ - Nome científico } & $T_{1}(2004)$ \\
\hline & IVI & & IVI \\
\hline Lecythis idatimon & 18,56 & Lecythis idatimon & 18,73 \\
\hline Rinorea flavescens & 15,83 & Rinorea flavescens & 16,35 \\
\hline Poecilanthe effusa & 15,82 & Poecilanthe effusa & 16,22 \\
\hline Eschweilera grandiflora & 13,60 & Eschweilera pedicellata & 13,95 \\
\hline Eschweilera pedicellata & 13,20 & Eschweilera grandiflora & 13,94 \\
\hline Inga sp. & 9,63 & Inga sp. & 10,01 \\
\hline Vouacapoua americana & 7,72 & Vouacapoua americana & 7,51 \\
\hline Protium spp. & 6,92 & Protium spp. & 7,25 \\
\hline Pouteria oppositifolia & 6,41 & Pouteria oppositifolia & 6,44 \\
\hline Guatteria poeppigiana & 5,53 & Pouteria macrocarpa & 5,82 \\
\hline TOTAL & 113,2 & & 116,2 \\
\hline
\end{tabular}




\begin{tabular}{lccc}
\hline Tabela 5 - Continuação & & & \\
\hline \multirow{2}{*}{ Nome científico } & $\mathrm{T}_{2}(2003)$ & \multirow{2}{*}{ Nome científico } & $\mathrm{T}_{2}(2004)$ \\
\cline { 2 - 4 } & $\mathrm{IVI}$ & & $\mathrm{IVI}$ \\
\hline Lecythis idatimon & 22,59 & Lecythis idatimon & 21,90 \\
Poecilanthe effusa & 17,28 & Poecilanthe effusa & 17,24 \\
Rinorea flavescens & 15,40 & Eschweilera grandiflora & 16,36 \\
Eschweilera grandiflora & 15,02 & Rinorea flavescens & 15,49 \\
Eschweilera pedicellata & 12,02 & Eschweilera pedicellata & 12,68 \\
Inga sp. & 10,41 & Protium spp. & 11,33 \\
Protium spp. & 10,23 & Inga sp. & 11,17 \\
Guatteria poeppigiana & 9,22 & Guatteria poeppigiana & 9,14 \\
Vouacapoua americana & 7,53 & Vouacapoua americana & 7,67 \\
Pseudopiptadenia suaveolens & 5,09 & Eschweilera coriacea & 5,53 \\
TOTAL & 124,8 & & 128,5 \\
\hline
\end{tabular}

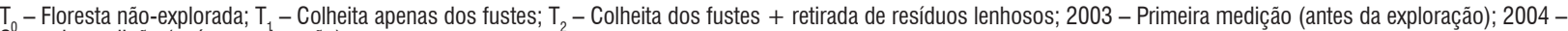
Segunda medição (após a exploração).

Como era de se esperar, nas parcelas-testemunhas não houve alteração entre as espécies mais importantes da primeira para a segunda medição. Entretanto, nos dois tratamentos (parcelas exploradas) algumas espécies mudaram de posição na hierarquia da importância, principalmente devido à colheita de árvores.

Guatteria poeppigiana (envira-preta), antes da exploração, aparecia entre as dez espécies de maior importância do $T_{1}$ (colheita apenas dos fustes), descendo para a $12^{\mathrm{a}}$ posiçáo, dando lugar para Pouteria macrocarpa, que teve um pequeno aumento em área basal. Da mesma forma, Pseudopiptadenia suaveolens estava entre as dez mais importantes no $\mathrm{T}_{2}$ (colheita dos fustes + retirada de resíduos), perdeu sua colocação para Eschweilera coriacea que teve um pequeno aumento em área basal e, conseqüentemente, no IVI.

Ao observar a Tabela 5, foi verificado que o reduzido número de espécies mais importantes (10) representa grande parcela de contribuição para o índice de valor de importância, corroborando as afirmativas de Mori et al. (1989) de que um número relativamente pequeno de espécies contribui para a maioria do valor do índice de importância de uma determinada floresta.

\section{CONCLUSÕES}

A estrutura da floresta dentro da área onde foram colhidos apenas os fustes comerciais, assim como na área onde, além da colheita dos fustes, foram também colhidos os resíduos lenhosos, sofreu alteração significante (abundância e dominância) em conseqüência da exploração florestal a que foram submetidas, de acordo com o teste t para amostras independentes a $95 \%$ de probabilidade. Entretanto, não houve alteraçóes significantes entre as duas áreas (teste t para amostras pareadas ao nível de $95 \%$ de probabilidade), demonstrando que, em termos ecológicos, a retirada dos resíduos lenhosos após a colheita dos fustes não causa danos significativos à floresta residual, composta por árvores com DAP $\geq 10 \mathrm{~cm}$.

A estrutura da floresta, mesmo com pequenas alteraçóes, não mostrou significância entre os três tratamentos (floresta náo-explorada, floresta onde houve colheita de fustes comerciais, e floresta onde houve colheita dos fustes comerciais e dos resíduos lenhosos), sugerindo que com a realização do manejo adequado, mesmo com a retirada adicional dos resíduos, após a colheita de madeira, aplicando técnicas de exploraçáo de impacto reduzido, a floresta deve continuar com suas características bem semelhantes à floresta original, embora em processo de recuperação do estoque volumétrico.

\section{BIBLIOGRAFIA CITADA}

Amaral, I.L.; Matos, F.D.A.; Lima, J. 2000. Composição florística e parâmetros estruturais de um hectare de floresta densa de terra firme no Rio Uatumá, Amazônia, Brasil. Acta Amazonica, 30(3): 377 - 392.

Ayres, M.; Ayres Júnior, M.; Ayres, D. L.; Santos, A. de A. S. dos. 2005. BioEstat - Aplicaçóes estatísticas nas áreas das ciências BioMédicas. Belém: Imprensa Oficial do Estado do Pará, 324pp.

Barros, A.V. de; Barros, P.L.C. de; Silva, L.C.B. da. 2000. Análise fitossociológica de uma floresta situada em Curuá-Una - Pará. Revista de Ciências Agrárias, 34: 9 - 36.

Bastos, T.X.; Rocha, A.M.A.; Pacheco, N.A.; Sampaio, S.M.N. 1993. Efeito da remoção da floresta ombrófila sobre regime pluviométrico no município de Paragominas - PA. Boletim de Geografia Teorética, 23 (45/46): 85-92.

Brasil. Departamento Nacional de Produção Mineral. Levantamento de recursos minerais. 1973. Folha SA.23 - São Luís e parte da folha SA.24 - Fortaleza. Geologia, geomorfologia, solos, vegetação e uso potencial da terra.Vol.3. Ministério de Minas e Energia, Rio de Janeiro.

Brasil. Departamento Nacional de Produção Mineral. Levantamento de recursos minerais. 1974. Folha SA.22 - Belém. Geologia, 
geomorfologia, solos, vegetação e uso potencial da terra. Vol.5. Ministério de Minas e Energia, Rio de Janeiro.

Carvalho, J. O. P. de. 1992. Structure and dynamics of a logged over Brasilian Amazonian rain forest. D. Phil. Thesis - University of Oxford, Oxford, 215pp

Finol U., H. 1971. Nuevos parámetros a considerarse en el análisis estructural de las selvas vírgenes tropicales. Revista Forestal Venezolana, 14(21): 29 - 42.

Gomide, G. L. A. 1997. Estrutura e dinâmica de crescimento de florestas tropicais primária e secundária no estado do Amapá. Dissertação de Mestrado, Universidade Federal do Paraná, Curitiba, Paraná, $179 \mathrm{pp}$.

Ibge. Instituto Brasileiro de Geografia e Estatística. 1991. Sinopse preliminar do censo demográfico 1991. IBGE, Rio de Janeiro. $74 \mathrm{pp}$.

Jardim, F.C.S.; Hosokawa, R.T. 1986/87. Estrutura da floresta equatorial úmida da estação experimental de silvilcultura tropical do INPA. Acta Amazonica, 16/17: 411 - 508.

Lamprecht, H. 1964. Ensayo sobre la estructura floristica de la parte sur-oriental del bosque universitario "El Caimital" - Estado Barinas. Revista Forestal Venezolana, 7(10/11): 77 - 119.

Leal, G. L. R. 2000. Paragominas: A realidade do pioneirismo. Alves. Belém. 498pp.

Maciel, M.N.M.; Queiroz, W.T.; Oliveira, F.A. 2000. Parâmetros fitossociológicos de uma floresta tropical de terra firme na Floresta Nacional de Caxiuanã (PA). Revista de Ciências Agrárias, 34: $85-106$.

Martins, S. S.; Couto, L.; Machado, C. C.; Souza, A. L. de. 2003. Efeito da exploraçáo florestal seletiva em uma floresta estacional semidecidual. Revista Árvore, 27(1): 65 - 70.

Matos, F. D. de A.; Amaral, I. L. do. 1999. Análise ecológica de um hectare em floresta ombrófila densa de terra firme, Estrada de Várzea, Amazonas, Brasil. Acta Amazonica, 29(3): 365 - 379.

Miranda, I. S. 2000. Análise florística e estrutural da vegetação lenhosa do Rio Comemoração, Pimenta Bueno, Rondônia, Brasil. Acta Amazonica, 30(3): 393 - 422.

Mori, S. A.; Rabelo, B. V.; Tsou, C.; Daly, D. 1989. Composition and structure of an eastern Amazonian forest at Camaipi, Amapa, Brazil. Boletim do Museu Paraense Emílio Goeldi, Botânica, 5(1): 3- 18 .

Richards, P. W. 1996. The tropical rain forest: an ecological study. New York: Cambridge University Press, 575pp.

Pantoja, F.B.C.; Oliveira, V.C.; Costa, L.G.S.; Vasconcelos, P.C.S. 1997. Estrutura de um trecho de floresta secundária de terra firme, no Município de Benevides, PA. FCAP / Serviço de documentação e informação (FCAP, Informe Técnico, 24), Belém. 18pp.

Pinto, A. C. M.; Souza, A. L. de; Souza, A. P. de; Machado, C. C.; Minette, L. J.; Vale, A. B. do. 2002. Análise de danos de colheita de madeira em floresta tropical úmida sob regime de manejo florestal sustentado na Amazônia Ocidental. Revista Árvore, 26(4): 459 - 466.

Sandel, M.P.; Carvalho, J.O.P. 2000. Composição florística e estrutura de uma área de cinco hectares de mata alta sem babaçu na Floresta Nacional do Tapajós. Belém: Embrapa Amazônia Oriental (Embrapa Amazônia Oriental. Documentos, 63), 19pp.

Silva, J.N.M.; Lopes, J.C.A. 1984. Inventário florestal contínuo em florestas tropicais: a metodologia da EMBRAPA-CPATU na Amazônia brasileira. EMBRAPA-CPATU (EMBRAPA-CPATU. Documentos, 33), Belém. 36pp.

Silva, J.N.M.; Lopes, J.C.A.; Oliveira, L.C.; Silva, S.M.A.; Carvalho, J.O.P.; Costa, D.H.M.; Melo, M.S.; Tavares, M.J.M. 2005. Diretrizes para Instalação e Medição de Parcelas Permanentes em Florestas Naturais da Amazônia Brasileira. Embrapa / ITTO, Belém. 68pp.

Silva, R.C. 1997. Contribuição do levantamento de solo e caracterização dos sistemas naturais e ambientais na regiāo de Paragominas - Estado do Pará. Dissertação de Mestrado, Faculdade de Ciências Agrárias do Pará, Belém, Pará. 107pp.

Veloso, H. P.; Rangel Filho, A. L. R.; Lima, J. C. A. 1991. Classificação da vegetação brasileira adaptada a um sistema universal. Rio de Janeiro: IBGE, Departamento de recursos naturais e estudos ambientais, 124pp.

Vidal, E.; Viana, V.; Batista, J. L. F. 1998. Efeitos da exploração madeireira predatória e planejada sobre a diversidade de espécies na Amazônia Oriental. Revista Árvore, 22(4): 503 - 520.

Watrin, O.S.; Rocha, A.M.A. 1992. Levantamento de vegetação natural e uso da terra no Município de Paragominas (PA) utilizando imagens TM/Landsat. EMBRAPA-CPATU (EMBRAPACPATU. Boletim de Pesquisa, 124), Belém, Pará. 40pp.

Recebido em 14/11/2008

Aceito em 19/03/2009 
